\title{
Serum free light chain level at diagnosis in myeloma cast nephropathy - a multicentre study
}

\author{
Punit Yadav ${ }^{1,2}$, Insara Jaffer Sathick ${ }^{3}$, Nelson Leung ${ }^{3}$, Elizabeth E. Brown ${ }^{4}$, Mark Cook ${ }^{5}$, Paul W. Sanders ${ }^{6,7}$ and \\ Paul Cockwell ${ }^{1,2}$
}

\begin{abstract}
Myeloma cast nephropathy (MCN) is a common cause of severe renal impairment in multiple myeloma (MM). The level of free light chain (FLC) that causes MCN varies substantially and there is uncertainty about the threshold level that should be used to inform clinical practice. In a multicentre cohort study of 103 patients with a diagnosis of MM and biopsy-confirmed MCN made between 2002-2014, we report prospectively measured levels of serum FLC at diagnosis obtained using a single nephelometric assay (Freelite ${ }^{\circledR}$ ) and we explore the relationship between serum FLC level at diagnosis with renal outcome and patient survival. Using a landmark approach, overall survival (OS) was compared between patients who achieved independence from dialysis compared to those who remained dialysis dependent at 3-month, 6-month, 9-month, and 12-month time points. The median serum FLC level at diagnosis was $7531 \mathrm{mg} / \mathrm{L}$ (range 107-114600). Serum creatinine was $535 \mu \mathrm{mol} / \mathrm{L}$ (range 168-2993) and eGFR $7 \mathrm{ml} / \mathrm{min} / 1.73 \mathrm{~m}^{2}$ (range 1-34). Six patients (5.8\%) had an FLC level $<1500 \mathrm{mg} / \mathrm{L}$, which is the International Myeloma Working Group threshold for MCN and two patients were below the International Kidney and Monoclonal Gammopathy working group threshold of $500 \mathrm{mg} / \mathrm{L}$; one was hypercalcaemic, and one had high-normal serum calcium level and had received a non-steroidal anti-inflammatory agent. Sixty-nine (67\%) patients required haemodialysis treatment of whom $36(52.1 \%)$ recovered independent renal function. Sixty-six (64\%) patients died with a median OS of 2.5 years $(95 \% \mathrm{Cl}$ 1.8-3.3). A landmark analysis revealed that independence from dialysis was associated with improved survival at 3months $(P=0.003)$, 6-months $(P=0.035)$ and 9-months $(P=0.014)$; there was no survival benefit observed beyond 12 months $(P=0.146)$. Serum FLC level at diagnosis was neither associated with renal function recovery nor with OS. This is the largest reported cohort of patients with biopsy-confirmed MCN and prospectively measured serum FLC levels. These results indicate that a serum monoclonal FLC $>500 \mathrm{mg} / \mathrm{L}$ should be considered the threshold level associated with the development of MCN.
\end{abstract}

\section{Introduction}

Renal function impairment (RI) is reported in up to 50\% of patients with multiple myeloma (MM) at presentation $^{1-6}$. Severe RI as defined by an estimated glomerular filtration rate $(\mathrm{eGFR})<30 \mathrm{ml} / \mathrm{min} / 1.73 \mathrm{~m}^{2}$ is present in up to $20 \%$ of patients with $\mathrm{MM}$ at diagnosis ${ }^{7}$, which

\footnotetext{
Correspondence: Paul Cockwell (paul.cockwell@uhb.nhs.uk)

'Department of Renal Medicine, University Hospitals Birmingham NHS Foundation Trust, Birmingham, UK

${ }^{2}$ Institute of Inflammation and Ageing, University of Birmingham, Birmingham, UK

Full list of author information is available at the end of the article.
}

approximates to the level of renal dysfunction defined by the renal component of the end-organ damage (hypercalcemia $[C]$, renal failure $[R]$, anaemia $[A]$, or bone lesions $[\mathrm{B}]$, herein referred to as CRAB) classification system $^{8}$. The predominant cause for severe RI is the pathognomonic distal tubular lesion, myeloma cast nephropathy $(\mathrm{MCN})$, which is a direct consequence of the secreted monoclonal immunoglobulin (Ig) free light chain $(\mathrm{FLC})^{9}$. The level of pathogenic serum FLC that causes $\mathrm{MCN}$ varies substantially and there is uncertainty about the threshold level that should be used to inform clinical practice $^{10}$.

\section{(c) The Author(s) 2020}

(c) (i) Open Access This article is licensed under a Creative Commons Attribution 4.0 International License, which permits use, sharing, adaptation, distribution and reproduction cc) in any medium or format, as long as you give appropriate credit to the original author(s) and the source, provide a link to the Creative Commons license, and indicate if changes were made. The images or other third party material in this article are included in the article's Creative Commons license, unless indicated otherwise in a credit line to the material. If material is not included in the article's Creative Commons license and your intended use is not permitted by statutory regulation or exceeds the permitted use, you will need to obtain permission directly from the copyright holder. To view a copy of this license, visit http://creativecommons.org/licenses/by/4.0/. 
A paradigm shift in the management of patients with MM has been the development of the serum FLC assay ${ }^{11}$, which is now the test recommended by the International Myeloma Working Group (IMWG) for the screening of patients with a suspected paraproteinemia ${ }^{12}$. The IMWG recently revised the criteria for the diagnosis of $M M$ in cases without CRAB features to include an involved to uninvolved serum FLC ratio $>100$ in association with an involved FLC level above $100 \mathrm{mg} / \mathrm{L}$, clonal bone marrow plasma cells $\geq 60$ percent, or more than one focal bone lesion $(>5 \mathrm{~mm})$ identified using magnetic resonance imaging $^{13}$.

The serum FLC assay is used in patients with unexplained acute kidney injury (AKI) to screen for potential MCN. However, the range of FLC at which MCN can occur is uncertain. The IMWG associated RI as a consequence of MCN to a serum FLC level above $1500 \mathrm{mg} /$ $\mathrm{L}^{13}$, whereas the International Kidney and Monoclonal Gammopathy (IKMG) Research Group proposed a serum FLC level above $500 \mathrm{mg} / \mathrm{L}^{14}$. We recently analysed the Myeloma IX study and found that an FLC level above $800 \mathrm{mg} / \mathrm{L}$ had the highest sensitivity and specificity for severe RI defined by an estimated glomerular filtration rate (eGFR) $<30 \mathrm{ml} / \mathrm{min} / 1.73 \mathrm{~m}^{2}$ at diagnosis ${ }^{15}$. However that study did not include patients who required dialysis and information on renal histology was not available. Additionally, it is also uncertain if the level of FLC in serum at presentation is an independent determinant of outcome in patients with AKI and MCN.
Therefore, the aim of this study was to primarily report the range of FLC levels in serum in patients with newly diagnosed MM who had AKI from renal biopsyconfirmed MCN. Additionally, we also report renal outcomes for those on dialysis and overall survival (OS) for the entire cohort.

\section{Patient and methods}

This was a multicentre study of newly diagnosed patients with MM and with biopsy-confirmed MCN between 2002 and 2014. Patients had presented at three tertiary centres: University Hospital Birmingham NHS Foundation Trust (UHB), Birmingham, UK; Mayo Clinic, Rochester, Minnesota, USA and; University of Alabama at Birmingham (UAB), Birmingham, Alabama, USA. We evaluated prospectively measured levels of involved FLC in serum using a single nephelometric assay (Freelite ${ }^{\circledR}$, The Binding Site, Birmingham, UK). Informed consent was obtained from all patients. Approval for conduct of this study was obtained from the local ethics committee or the Institutional Review Board from the three centres in accordance with the Declaration of Helsinki.

Figure 1 is a CONSORT diagram showing the characteristics of patients included in the study. Inclusion criteria comprised all patients with a new diagnosis of MM and biopsy proven MCN. Patients that were excluded from analysis comprised: (a) those with relapsing/ remitting MM; (b) those known to have chronic kidney disease (CKD); (c) renal transplant recipients; (d) those with a histological diagnosis of $\mathrm{MCN}$ and other

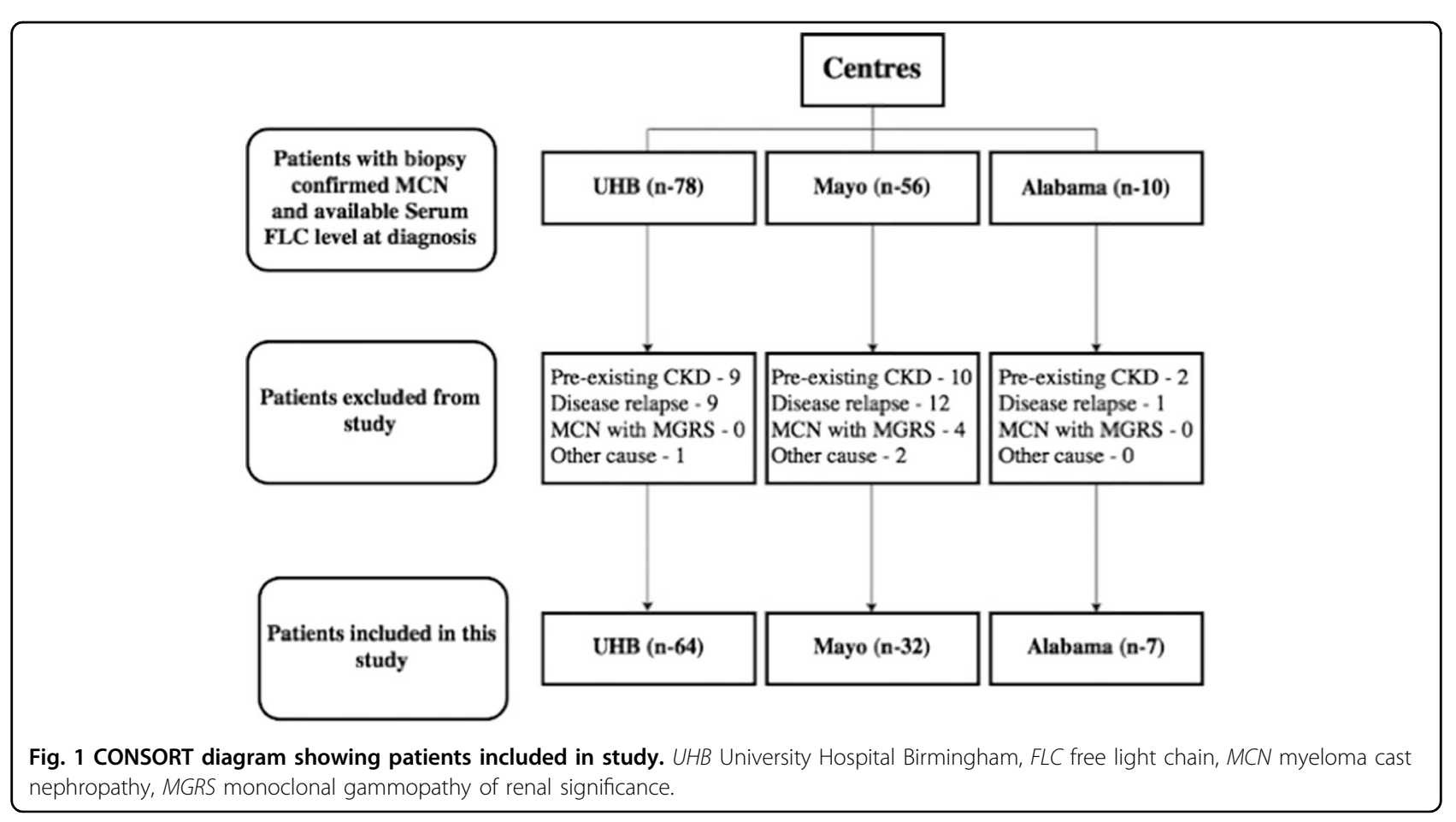


paraproteinemia e.g. amyloidosis, renal monoclonal immunoglobulin deposition diseases, or any other monoclonal gammopathy of renal significance (MGRS); and (e) patients in whom serum FLC levels were measured after commencement of anti-myeloma therapy.

Variables included in the analysis were: patient age at diagnosis, gender, ethnicity, date of presentation with RI, Modification of Diet in Renal Disease study equation (MDRD) eGFR $\left(\mathrm{ml} / \mathrm{min} / 1.73 \mathrm{~m}^{2}\right)$, corrected serum calcium, haemoglobin, paraprotein and FLC type, serum FLC level at presentation, date of renal biopsy, days from presentation to renal biopsy, days from presentation to receipt of first dialysis, date of dialysis independence, duration of dialysis, percentage of plasma cell infiltrate in the bone marrow, OS and time to death.

Statistical analysis was performed using SPSS $^{\circledR}$ for Windows, version 21.0 (SPSS Inc, Chicago, IL) and Graph Pad Prism 5.0 (GraphPad Software Inc, San Diego, CA). Categorical variables were summarised as frequencies and percentages. Comparisons for categorical variables among different groups were made with the chi-square test and Fisher's exact test where appropriate. Continuous variables were expressed as mean and standard deviation (SD) if the data was normally distributed or median with range for non-normally distributed data. Non-parametric comparisons were performed by using the Mann-Whitney $U$ test. Correlation analysis between patients presenting with eGFR $<15 \mathrm{ml} / \mathrm{min} / 1.73 \mathrm{~m}^{2}$ irrespective of haemodialysis status at diagnosis and serum FLC levels was performed with Spearman's rank test. In addition to reporting levels of FLC in serum that were associated with $\mathrm{MCN}$, we also examined variables collected at presentation that correlated with renal function recovery in patients on haemodialysis and OS. For patients on haemodialysis, renal function recovery was defined as a sustained independence from dialysis treatment for at least two months. Patients were followed until death from any cause or censored on $31^{\text {st }}$ December 2014, if they were still alive at this date, for survival analysis. In order to reduce the possibility for lead-time bias, OS for patients who achieved independence from haemodialysis and were alive were compared with OS for patients who were haemodialysis dependent and alive in a landmark analysis at 3 months, 6 months, 9 months months after presentation with a new diagnosis of $\mathrm{MCN}$. Patients who died before the landmark time were excluded and OS for the landmark analysis was performed from the landmark time to death. Outcomes in patients with MM have progressively improved with time due to the advances in supportive care and introduction of novel anti-myeloma therapies. From 2008, the chemotherapy regimens based on the proteasome inhibitor bortezomib became the standard of care for MM and severe AKI, and hence differences in survival were compared between those diagnosed with MCN before and after this time-point. All statistical tests were two sided and a $P$ value of $<0.05$ was considered as significant.

\section{Results \\ Patient demographic and disease characteristics}

103 patients with incident MM, with no previous history of CKD, serum FLC level available at diagnosis and histologically confirmed MCN by renal biopsy were included in the study. Table 1 summarises the baseline characteristics of patients in the study. The median age at presentation was 63 years (range 38-85), 57.3\% were of male gender, and $88.3 \%$ were white. Light chain restricted MM (47.6\%) was the predominant paraprotein type. An involved monoclonal kappa ( $\mathrm{K}$ ) FLC isotype was present in $54.4 \%$ and an involved lambda ( $\lambda$ ) FLC in $45.6 \%$ of patients.

The median involved serum FLC level at presentation was $7531 \mathrm{mg} / \mathrm{L}$ (range 107-114,600). Distribution of FLC levels in serum for the entire cohort is presented in Fig. 2. There was no significant difference in the levels of FLC in serum for patients presenting with involved $\kappa$ FLC or involved $\lambda$ FLC isotypes $(P=0.211)$. Two $(1.9 \%)$ patients presented with an involved serum FLC level that was $\leq 500 \mathrm{mg} / \mathrm{L}$ at diagnosis; one patient was hypercalcaemic, and the other patient had a high-normal serum calcium level and was on a non-steroidal anti-inflammatory drug.

\section{Renal characteristics at diagnosis}

Sixty-nine $(66.9 \%)$ patients required haemodialysis after the diagnosis of MCN. Of these 51 patients received extracorporeal treatment; 31 with plasma exchange (PE, Mayo Clinic and UAB) and 21 with high-cut off haemodialysis (HCO-HD, UHB). The median time from presentation to start of haemodialysis was one day (range 0-202); two patients started haemodialysis 30 days after presentation (day 49 and day 202, respectively). There was no significant difference in serum FLC levels in patients presenting with eGFR $<15 \mathrm{ml} / \mathrm{min} / 1.73 \mathrm{~m}^{2}$ at diagnosis irrespective of haemodialysis status (median serum FLC level in patients not requiring haemodialysis $7444 \mathrm{mg} / \mathrm{L}$ [range 575-32,294] and $8643 \mathrm{mg} / \mathrm{L}$ [range 580-114,600] for those requiring haemodialysis, $P=$ 0.895) (Fig. 3).

\section{Renal outcomes and patient survival}

Thirty-four (33\%) patients had no requirement for haemodialysis treatment at diagnosis. For the 69 (66.9\%) patients who required haemodialysis at diagnosis, 36 (52.1\%) achieved recovery of renal function. The median duration of haemodialysis treatment was 36 days (range 10-701).

We found no significant difference in age, eGFR, corrected calcium, haemoglobin, and involved serum FLC 
Table 1 Patient characteristics.

\begin{tabular}{|c|c|c|c|c|}
\hline & $\begin{array}{l}\text { All patients } \\
(n=103)\end{array}$ & $\begin{array}{l}\text { Patients not requiring } \\
\text { dialysis }(n=34)\end{array}$ & $\begin{array}{l}\text { Patients requiring dialysis and } \\
\text { recovering renal function } \\
(n=36)\end{array}$ & $\begin{array}{l}\text { Patients requiring dialysis and } \\
\text { not recovering renal function } \\
(n=33)\end{array}$ \\
\hline \multicolumn{5}{|l|}{ Centres } \\
\hline UHB & $64(62.1)$ & $14(41.1)$ & $27(75.0)$ & $23(69.7)$ \\
\hline Mayo & $32(31.1)$ & $17(50.0)$ & $7(19.4)$ & $8(24.2)$ \\
\hline$U A B$ & $7(6.8)$ & $3(8.8)$ & $2(5.5)$ & $2(6.0)$ \\
\hline Age (years) & $63(38-85)$ & $64(38-84)$ & $60(43-72)$ & $65(45-85)$ \\
\hline \multicolumn{5}{|l|}{ Gender } \\
\hline Male & $59(57.3)$ & $19(55.9)$ & $25(69.4)$ & $15(45.4)$ \\
\hline Female & $44(42.7)$ & $15(44.1)$ & $11(30.5)$ & $18(54.5)$ \\
\hline \multicolumn{5}{|l|}{ Ethnicity } \\
\hline White & $91(88.3)$ & $32(94.1)$ & $30(83.3)$ & $29(87.8)$ \\
\hline Non-white & $12(11.6)$ & $2(5.8)$ & $6(16.6)$ & $4(12.1)$ \\
\hline \multicolumn{5}{|l|}{ Paraprotein type } \\
\hline Light chain restricted MM & $49(47.6)$ & $14(41.1)$ & $15(41.6)$ & $20(60.6)$ \\
\hline Whole Ig MM & $54(52.4)$ & $20(58.8)$ & $21(58.3)$ & $13(39.3)$ \\
\hline \multicolumn{5}{|l|}{ FLC isotype } \\
\hline Kappa $(\kappa)$ & $56(54.4)$ & $16(47)$ & $19(52.7)$ & $21(63.6)$ \\
\hline Lambda $(\lambda)$ & $47(45.6)$ & $18(52.9)$ & $17(47.2)$ & $12(36.3)$ \\
\hline \multicolumn{5}{|l|}{ FLC level (mg/L) } \\
\hline $\begin{array}{l}\text { FLC level irrespective of } \\
\text { isotype }\end{array}$ & $7531(107-114,600)$ & $6724(107-32,294)$ & $7960(580-43,161)$ & $10134(1620-114,600)$ \\
\hline k FLC level & $6965(201-46,000)$ & $6474(201-32,294)$ & $7844(580-28,622)$ & $9302(1620-46,000)$ \\
\hline$\lambda \mathrm{FLC}$ level & $8220(107-114,600)$ & $6853(107-20,000)$ & $8108(1971-43161)$ & $12667(1760-114,600)$ \\
\hline Serum creatinine $(\mu \mathrm{mol} / \mathrm{L})$ & 535 (168-2993) & $349(168-1141)$ & 685 (329-2210) & 778 (265-2993) \\
\hline eGFR $\left(\mathrm{ml} / \mathrm{min} / 1.73 \mathrm{~m}^{2}\right)$ & $7(1-34)$ & $12(3-34)$ & $6(2-15)$ & $5(1-17)$ \\
\hline Haemoglobin (g/L) & $90(46-131)$ & $99(54-129)$ & $86(56-131)$ & $86(46-126)$ \\
\hline Corrected calcium ( $\mathrm{mmol} / \mathrm{L})$ & $2.35(1.65-4.25)$ & $2.38(1.96-4.25)$ & $2.32(1.65-3.27)$ & $2.43(1.97-4.23)$ \\
\hline $\begin{array}{l}\text { Percentage plasma cell } \\
\text { infiltrate on bone marrow }\end{array}$ & $55(1-90)$ & $60(1-85)$ & $50(10-90)$ & $55(20-90)$ \\
\hline
\end{tabular}

Mean \pm standard deviation or median (range) reported for continuous variables and frequency (percentage) reported for categorical variables. UHB University Hospital Birmingham, UAB University of Alabama at Birmingham, MM multiple myeloma, $l g$ immunoglobulin, FLC free light chain.

level at presentation between patients who required haemodialysis and recovered renal function compared to those who remained dialysis-dependent. There was no difference in the renal recovery rate for patients who received $\mathrm{PE}(P=0.282)$ or $\mathrm{HCO}-\mathrm{HD}$ compared to standard dialysis $(P=0.336)$.

Patients who did not require dialysis had higher haemoglobin concentration (median $98 \mathrm{~g} / \mathrm{L}$ [range 54-129] vs $86 \mathrm{~g} / \mathrm{L}$ [range 46-126] respectively, $P=0.010$ ), and lower involved serum FLC level (median $6724 \mathrm{mg} / \mathrm{L}$ [range $107-32,294$ ] vs $10134 \mathrm{mg} / \mathrm{L}$ [range 1620-114,600],
$P=0.044)$ compared to those who remained dialysisdependent.

At the end of the follow-up period, 66 (64\%) patients had died. The median OS from diagnosis was 2.5 years (95\% CI 1.8-3.3). There was no significant difference in OS between patients who received haemodialysis at presentation (median 2.0 years; 95\% CI 0.9-3.1) compared to those who had no requirement for dialysis (median 3.5 years; 95\% CI 1.6-5.5) $(P=0.248)$. This finding was unchanged in an analysis that excluded the patient who started haemodialysis on day 202 after the diagnosis of 
MCN. Patients who received haemodialysis at diagnosis and subsequently recovered renal function showed a significantly improved OS (median 3.3 years, 95\% CI 1.6-5.0) compared to those who remained dialysisdependent (median 0.8 years, 95\% CI $0.6-1.0$ ) $(P<0.0001)$. On performing a landmark analysis, independence from dialysis at 3 -month $(P=0.003), 6$-month $(P=0.035)$ and 9-month $(P=0.014)$ time points were
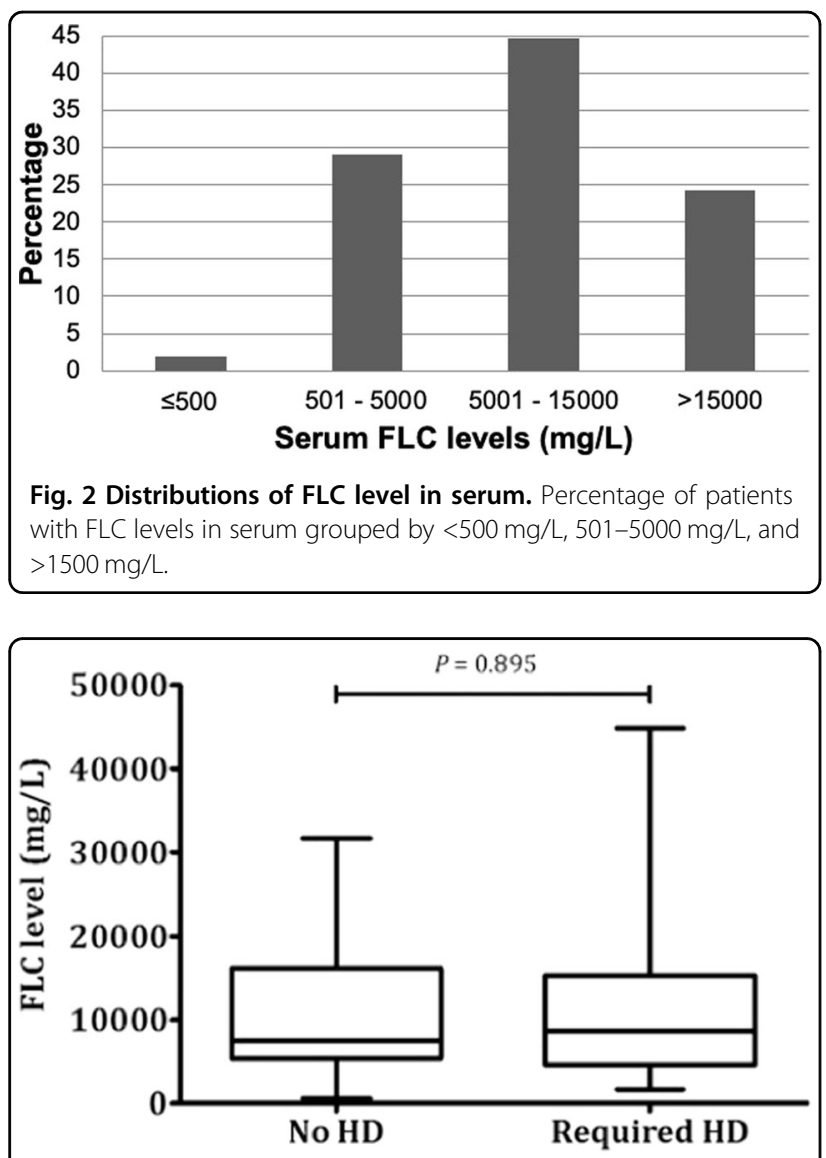

Fig. 3 Serum FLC levels at diagnosis. Box-plot of serum FLC levels at diagnosis in patients presenting with eGFR $<15 \mathrm{ml} / \mathrm{min} / 1.73 \mathrm{~m}^{2}$ by dialysis status (HD, haemodialysis). associated with improved survival whereas no such survival benefit was observed beyond 12 months $(P=0.146)$ (Table 2).

The median OS amongst patients who presented after 2008 was 3.8 years (95\% CI 2.5-5.1) and was significantly better compared to those who presented before 2008 (median 1.7 years, 95\% CI 0.6-2.9) $(P<0.006)$. We found no statistically significant change in the rates of renal function recovery $(P=0.151)$ between those presenting before or after 2008 .

\section{Discussion}

In this multicentre study the principal findings were: (1) the variable range of FLC levels in serum that were observed in patients presenting with biopsy-confirmed MCN; (2) Six patients had an FLC level $<1500 \mathrm{mg} / \mathrm{L}$, the level recommend by the IMWG for MCN; (3) two of the 103 patients presented with FLC levels $\leq 500 \mathrm{mg} / \mathrm{L}$, both with precipitants for the development of cast nephropathy; (4) dialysis independence within 12 months was associated with better OS; and (5) the serum FLC level at presentation was not associated with renal function recovery or with patient survival.

This study is the largest analysis to date of the relationship between FLC level in serum and biopsyconfirmed MCN. To the best of our knowledge only thirty-five studies have reported on serum FLC level in patients with biopsy-confirmed $\mathrm{MCN}^{9,16-46}$. The median numbers of patients reported in these studies were 5 (range 1-98) and the median serum FLC levels at diagnosis where available were: involved $\kappa$ FLC $14,100 \mathrm{mg} / \mathrm{L}$ (range 80-42,000) and involved $\lambda$ FLC $4267 \mathrm{mg} / \mathrm{L}$ (range $855-69,430)$.

Immunoassays for serum FLC have only entered widespread clinical practice in the last decade and there is limited data on the relationship between serum FLC level and MCN. The IMWG in their recent revised diagnostic criteria for MM included RI caused by $\mathrm{MCN}$ as a myeloma defining event, where $\mathrm{MCN}$ was characterised by the presence of typical histological features or an involved

Table 2 Landmark analysis of associations between haemodialysis independence and overall survival in patients with MCN $(n=69)$.

\begin{tabular}{|c|c|c|c|c|c|c|c|c|}
\hline \multirow[b]{2}{*}{ Landmark time } & \multirow[b]{2}{*}{$\begin{array}{l}\text { Pts excluded } \\
\text { (n) }\end{array}$} & \multicolumn{3}{|c|}{ HD independent } & \multicolumn{3}{|c|}{ HD dependent } & \multirow[b]{2}{*}{$P$-value } \\
\hline & & Patients $(n)$ & $\begin{array}{l}\text { Deaths after } \\
\text { landmark time }(n)\end{array}$ & $\begin{array}{l}\text { Median OS } \\
\text { (years) }\end{array}$ & Patients $(n)$ & $\begin{array}{l}\text { Deaths after } \\
\text { landmark time }(n)\end{array}$ & $\begin{array}{l}\text { Median OS } \\
\text { (years) }\end{array}$ & \\
\hline 3 month & 9 & 35 & 22 & 3.85 & 25 & 21 & 1.12 & 0.003 \\
\hline 6 month & 17 & 34 & 21 & 3.85 & 18 & 15 & 1.73 & 0.035 \\
\hline 9 month & 19 & 32 & 19 & 4.23 & 18 & 15 & 1.72 & 0.014 \\
\hline 12 month & 25 & 31 & 18 & 4.23 & 13 & 10 & 2.93 & 0.146 \\
\hline
\end{tabular}


serum FLC level above $1500 \mathrm{mg} / \mathrm{L}^{13}$. The IKMG research group recommended an involved serum FLC level above $500 \mathrm{mg} / \mathrm{L}$ in patients with AKI as a threshold level for suspecting MCN and for consideration of an urgent haemato-oncological work up ${ }^{14}$. The results in the present study supports the IKMG threshold for MCN, as $5.8 \%$ of patients presented with a serum FLC level below $1500 \mathrm{mg} / \mathrm{L}$; these patients would have been at risk of misdiagnosis if using the IMWG threshold for MCN. In a recent analysis of the myeloma IX clinical trial we found $22.7 \%$ of patients had a serum FLC level $>1500 \mathrm{mg} / \mathrm{L}$ at presentation whereas $43.7 \%$ had serum FLC $>500 \mathrm{mg} / \mathrm{L}$. In the same study, renal impairment defined as an eGFR $<60 \mathrm{ml} / \mathrm{min} / 1.73 \mathrm{~m}^{2}$ was noted in $71.4 \%$ of patients with serum FLC level above $1500 \mathrm{mg} / \mathrm{L}$, and this was $60.6 \%$ in patients with serum FLC levels $>500 \mathrm{mg} / \mathrm{L}^{15}$. Importantly this study showed that patients could have a very high FLC level and no RI at diagnosis. This is consistent with experimental work which shows that each FLC has a specific level for precipitation. Animal studies also showed that the threshold for cast formation is lower in the presence of a co-precipitant ${ }^{10}$. The two patients with FLC levels $\leq 500 \mathrm{mg} / \mathrm{L}$ had co-precipitating factors.

There is great interest in improving the time to diagnosis and commencement of treatment for MCN. Hence, defining the serum FLC levels associated with MCN using the above threshold is an important component of achieving this aim. This would help by averting the need for delays and risks associated with renal biopsy, and consequent delay in initiation of life and organ saving anti-myeloma treatment. In addition, knowledge of early changes in serum FLC levels from baseline after commencement of chemotherapy in patients with MCN may also direct early changes in therapy. There is evidence that early disease response defined by a reduction in serum FLC is associated with an increased probability of renal recovery ${ }^{47}$.

A secondary aim of this study was to assess the association between serum FLC levels at presentation with renal recovery and OS in this population of patients who presented with severe RI. This analysis was limited by the change in time frame over which the study was performed and missing details of the chemotherapy regimens used for some patients. To date there are no studies that have reported on the relationship between serum FLC levels at diagnosis in patients presenting with $\mathrm{MCN}$ and subsequent renal recovery. We found that the level of serum FLC level at presentation had no influence on whether or not patients who required dialysis subsequently recovered independent renal function or remained dialysisdependent.

There is however growing evidence that OS is improving substantially in patients with MM who require dialysis for $\mathrm{AKI}^{48}$; this improvement may be associated with increasing use of bortezomib-based regimens ${ }^{49}$. We did not have sufficient information on chemotherapy to perform an assessment of the impact of use of bortezomib, but by time-period we found a significantly better OS in patients who presented after 2008, the period when bortezomib came into widespread use for patients with MM and AKI, compared to patients who presented before $2008(P=0.006)$. Treatment of MM with bortezomibbased regimens became increasingly common after 2008 and the evidence in clinical and epidemiological studies for patients with MM and RI supports the benefits of this treatment ${ }^{30,48}$. The lack of association with extracorporeal removal of FLC is consistent with the major randomised controlled trials for plasma exchange and HCO-HD.in patients with $\mathrm{MM}$ and $\mathrm{AKI}^{46,50,51}$.

In conclusion, this is the largest study of the relationship between serum FLC levels and biopsy-confirmed MCN in patients with MM. $98 \%$ of patients with $\mathrm{MCN}$ at diagnosis presented with a serum FLC level $>500 \mathrm{mg} / \mathrm{L}$. Based on the findings from this study we propose that a serum FLC level $>500 \mathrm{mg} / \mathrm{L}$ should be considered for future diagnostic criteria for $\mathrm{MCN}$. This recommendation is only valid for the Freelite ${ }^{\circledR}$ FLC assay (The Binding Site, Birmingham) and validation with other FLC assays have not been performed. Serum FLC level at diagnosis was not associated with patient outcomes in MCN. Renal function recovery within 12 months was associated with improved survival in patients with $\mathrm{MCN}$ when compared to those who remained dialysis-dependent, no such benefit was observed after 12 months.

\section{Acknowledgements}

Dr. Sanders was supported by a Merit Award (2 101 CX001326) from the United States (U.S.) Department of Veterans Affairs Clinical Sciences R\&D (CSRD) Service, a National Institutes of Health George M. O'Brien Kidney and Urological Research Centres Program (P30 DK079337), and an Anderson Innovation Award. Dr. Brown was supported by grants from the National Cancer Institute (R01 CA186646)

\footnotetext{
Author details

${ }^{1}$ Department of Renal Medicine, University Hospitals Birmingham NHS Foundation Trust, Birmingham, UK. ${ }^{2}$ Institute of Inflammation and Ageing, University of Birmingham, Birmingham, UK. ${ }^{3}$ Mayo Clinic, Rochester NY, USA. ${ }^{4}$ Department of Pathology, University of Alabama at Birmingham, Birmingham AL, USA. ${ }^{5}$ Department of Haematology, University Hospitals Birmingham NHS Foundation Trust, Birmingham, UK. ${ }^{6}$ Department of Medicine, University of Alabama at Birmingham, Birmingham, AL, USA. ${ }^{7}$ Birmingham Veterans Affairs Medical Center, Birmingham, AL, USA
}

\section{Author contributions}

P.Y., P.W.S., N.L. and P.C. were involved in study design, data collection, data interpretation, and writing of the manuscript; and I.J.S., E.E.B. and M.C. were involved in data collection, data interpretation, and writing of the manuscript. The paper was reviewed and approved by all authors, and the corresponding author had the final responsibility over the decision to submit for publication.

\section{Conflict of interest}

P.C. is a medical advisor to the The Binding Site. The remaining authors declare that they have no conflict of interest. 


\section{Publisher's note}

Springer Nature remains neutral with regard to jurisdictional claims in published maps and institutional affiliations.

Received: 27 March 2019 Revised: 29 July 2019 Accepted: 23 August 2019 Published online: 03 March 2020

\section{References}

1. Augustson, B. M. et al. Early mortality after diagnosis of multiple myeloma: analysis of patients entered onto the United kingdom Medical Research Council trials between 1980 and 2002-Medical Research Council Adult Leukaemia Working Party. J. Clin. Oncol. 23, 9219-9226 (2005).

2. Blade, J. et al. Renal failure in multiple myeloma: presenting features and predictors of outcome in 94 patients from a single institution. Arch. Intern. Med. 158, 1889-1893 (1998).

3. Knudsen, L. M., Hjorth, M. \& Hippe, E. Renal failure in multiple myeloma: reversibility and impact on the prognosis. Nordic Myeloma Study Group. Eur. J. Haematol. 65, 175-181 (2000).

4. Kyle, R. A. et al. Review of 1027 patients with newly diagnosed multiple myeloma. Mayo Clin. Proc. 78, 21-33 (2003).

5. Yadav, P., Cook, M. \& Cockwell, P. Current trends of renal impairment in multiple myeloma. Kidney Dis. (Basel) 1, 241-257 (2016).

6. Knudsen, L. M., Hippe, E., Hjorth, M., Holmberg, E. \& Westin, J. Renal function in newly diagnosed multiple myeloma-a demographic study of 1353 patients. The Nordic Myeloma Study Group. Eur. J. Haematol. 53, 207-212 (1994).

7. Dimopoulos, M. A. et al. Significant improvement in the survival of patients with multiple myeloma presenting with severe renal impairment after the introduction of novel agents. Ann. Oncol. 25, 195-200 (2014).

8. International Myeloma Working, G. Criteria for the classification of monoclonal gammopathies, multiple myeloma and related disorders: a report of the International Myeloma Working Group. Br. J. Haematol. 121, 749-757 (2003).

9. Hutchison, C. A. et al. Immunoglobulin free light chain levels and recovery from myeloma kidney on treatment with chemotherapy and high cut-off haemodialysis. Nephrol. Dial. Transplant. 27, 3823-3828 (2012).

10. Sanders, P. W. \& Booker, B. B. Pathobiology of cast nephropathy from human Bence Jones proteins. J. Clin. Investig. 89, 630-639 (1992).

11. Bradwell, A. R. et al. Highly sensitive, automated immunoassay for immunoglobulin free light chains in serum and urine. Clin. Chem. 47, 673-680 (2001).

12. Dispenzieri, A. et al. International Myeloma Working Group guidelines for serum-free light chain analysis in multiple myeloma and related disorders. Leukemia 23, 215-224 (2009).

13. Rajkumar, S. V. et al. International Myeloma Working Group updated criteria for the diagnosis of multiple myeloma. Lancet Oncol. 15, e538-e548 (2014).

14. Hutchison, C. A. et al. The pathogenesis and diagnosis of acute kidney injury in multiple myeloma. Nat. Rev. Nephrol. 8, 43-51 (2012).

15. Yadav, P. et al. Serum free light chain levels and renal function at diagnosis in patients with multiple myeloma. BMC Nephrol. 19, 178 (2018).

16. Hutchison, C. A. et al. Treatment of acute renal failure secondary to multiple myeloma with chemotherapy and extended high cut-off hemodialysis. Clin. J. Am. Soc. Nephrol. 4, 745-754 (2009).

17. Hasegawa, M. et al. Evaluation of blood purification and bortezomib plus dexamethasone therapy for the treatment of acute renal failure due to myeloma cast nephropathy. Ther. Apher. Dial. 14, 451-456 (2010).

18. Sinisalo, M., Silvennoinen, R. \& Wirta, O. High cut-off hemodialysis and bortezomib-based therapy to rescue kidneys in myeloma-dependent cast nephropathy. Am. J. Hematol. 87, 640 (2012).

19. Khalafallah, A. A. et al. Early application of high cut-off haemodialysis for denovo myeloma nephropathy is associated with long-term dialysis-independency and renal recovery. Mediterr. J. Hematol. Infect. Dis. 5, e2013007 (2013).

20. Kourelis, T. V., Manola, A., Moustakakis, M. N. \& Bilgrami, S. F. Role of plasma exchange in the treatment of myeloma nephropathy: experience of one institution and systematic review. Conn. Med. 77, 147-151 (2013).

21. Tan, J., Lam-Po-Tang, M., Hutchison, C. A. \& de Zoysa, J. R. Extended high cutoff haemodialysis for myeloma cast nephropathy in Auckland, 2008-2012. Nephrology (Carlton) 19, 432-435 (2014).

22. Buus, N. H., Rantanen, J. M., Krag, S. P., Andersen, N. F. \& Jensen, J. D. Hemodialysis using high cut off filters in light chain cast nephropathy. Blood Purif 40, 223-231 (2015).
23. Rousseau-Gagnon, M., Agharazii, M., De Serres, S. A. \& Desmeules, S. Effectiveness of haemodiafiltration with heat sterilized high-flux polyphenylene HF dialyzer in reducing free light chains in patients with myeloma cast nephropathy. PloS ONE 10, e0140463 (2015).

24. Decourt, A. et al. Trends in survival and renal recovery in patients with multiple myeloma or light-chain amyloidosis on chronic dialysis. Clin. J. Am. Soc. Nephrol. 11, 431-441 (2016).

25. Borrego-Hinojosa, J. et al. Treatment by long haemodialysis sessions with high cut-off filters in myeloma cast nephropathy: our experience Nefrologia 33 515-523 (2013).

26. Ecotiere, L. et al. Prognostic value of kidney biopsy in myeloma cast nephropathy: a retrospective study of 70 patients. Nephrol. Dial. Transplant. $\mathbf{3 1}$ 64-72 (2016).

27. Curti, A., Schwarz, A., Trachsler, J., Tomonaga, Y. \& Ambuhl, P. M. Therapeutic efficacy and cost effectiveness of high cut-off dialyzers compared to conventional dialysis in patients with cast nephropathy. PlOS ONE 11, e0159942 (2016).

28. Jayaballa, M. et al. Effective removal of kappa-free light chains with hemodialysis using fresenius ultraflux(R) EMiC(R)2 dialyser in a patient with myeloma cast nephropathy, with associated cost savings. Blood Purif. 42 158-159 (2016).

29. Pradhan, D., Arora, P., Gami, A. \& Kaur, N. Immunoglobulin G kappa biclonal gammopathy associated with multiple myeloma, plasmacytoma and cast nephropathy. J. Cancer Res. Ther. 11, 660 (2015).

30. Yadav, P. et al. Patients with multiple myeloma have excellent long-term outcomes after recovery from dialysis-dependent acute kidney injury. Eur. J. Haematol. 96, 610-617 (2016).

31. Pasquali, S. et al. A novel option for reducing free light chains in myeloma kidney: supra-hemodiafiltration with endogenous reinfusion (HFR). J. Nephrol. 28, 251-254 (2015).

32. Weinstein, R. et al. Safety and efficacy of autologous hemopoietic progenitor cell collection in tandem with hemodialysis in multiple myeloma with myeloma cast nephropathy. J. Clin. Apher. 29, 83-89 (2014).

33. Hada, R., Poudyal, B., Sharma, A. \& Khatri, R. Lambda light chain myeloma with oliguric cast nephropathy and remission with bortezomib, doxorubicin and dexamethasone. JNMA J. Nepal Med. Assoc. 52, 192-195 (2012).

34. Mehta, S. et al. Use of continuous venovenous hemofiltration for acute renal failure due to multiple myeloma cast nephropathy. Hematology 17, 229-231 (2012).

35. Ward, F. et al. Successful use of combined high cut-off haemodialysis and bortezomib for acute kidney injury associated with myeloma cast nephropathy. Ir. Med. J. 105, 148-149 (2012).

36. Dahal, K. et al. Recovery of kidney function following delayed use of Theralite dialyzer in a patient with myeloma cast nephropathy. Clin. Nephrol. 79, 318-322 (2013).

37. Susantitaphong, P., Tiranathanagul, K. \& Eiam-Ong, S. Extended high cutoff online hemodiafiltration is superior to extended high cutoff hemodialysis in removal of free light chain immunoglobulin of myeloma cast nephropathy. Artif. Organs 36, 845-846 (2012).

38. Peters, N. O. et al. Impact of free light chain hemodialysis in myeloma cast nephropathy: a case-control study. Hemodial. Int. 15, 538-545 (2011).

39. Basnayake, $\mathrm{K}$ et al. Resolution of cast nephropathy following free light chain removal by haemodialysis in a patient with multiple myeloma: a case report. J. Med. Case Rep. 2, 380 (2008).

40. Leung, N. et al. Improvement of cast nephropathy with plasma exchange depends on the diagnosis and on reduction of serum free light chains. Kidney Int. 73, 1282-1288 (2008).

41. Basnayake, K. et al. Differential progression of renal scarring and determinants of late renal recovery in sustained dialysis dependent acute kidney injury secondary to myeloma kidney. J. Clin. Pathol. 63, 884-887 (2010)

42. Rassner, M. P. et al. Cast nephropathy and deceptively low absolute serum free light chain levels: resolution of a challenging case and systematic review of the literature. Clin. Lymphoma Myeloma Leuk. 18, e1-e7 (2018).

43. Snozek, C. L. H., Kinard, T. N. \& Adamski, J. Rapid reduction of extremely high kappa free light chains in a patient with myeloma cast nephropathy. J. Clin. Apher. 33, 439-443 (2018).

44. Kawabe, M. et al. Successful treatment of myeloma cast nephropathy using bortezomib-based chemotherapy plus selective plasma exchange. CEN Case Rep. 5, 232-237 (2016). 
45. Sethi, J. et al. Plasma exchange in the management of new onset multiple myeloma with cast nephropathy treated with bortezomib based chemotherapy. Nephrology (Carlton) 22, 1035-1036 (2017).

46. Bridoux, F. et al. Effect of high-cutoff hemodialysis vs conventional hemodialysis on hemodialysis independence among patients with myeloma cast nephropathy: a randomized clinical trial. JAMA 318, 2099-2110 (2017).

47. Hutchison, C. A. et al. Early reduction of serum-free light chains associates with renal recovery in myeloma kidney. J. Am. Soc. Nephrol. 22, 1129-1136 (2011)

48. Evison, F. et al. A population-based study of the impact of dialysis on mortality in multiple myeloma. Br. J. Haematol. 180, 588-591 (2016).
49. Uttervall, $K$. et al. The use of novel drugs can effectively improve response, delay relapse and enhance overall survival in multiple myeloma patients with renal impairment. PloS ONE 9, e101819 (2014).

50. Clark, W. F. et al. Plasma exchange when myeloma presents as acute renal failure: a randomized, controlled trial. Ann. Intern. Med. 143, 777-784 (2005).

51. Hutchison, C. A. et al. High cutoff versus high-flux haemodialysis for myeloma cast nephropathy in patients receiving bortezomib-based chemotherapy (EuLITE): a phase 2 randomised controlled trial. Lancet Haematol. 6, e217-e228 (2019). 